\title{
PELAYANAN PASIEN RAWAT JALAN PADA PUSKESMAS KABUPATEN GOWA
}

\author{
REZA MAULANA ${ }^{1}$ \\ Program Studi Sistem Informasi, Fakultas Sains dan Teknologi, Universitas Islam \\ Negeri Alauddin Makassar \\ E-mail: saya@rezamaulana.com
}

\begin{abstract}
ABSTRAK
Pelayanan Pasien rawat jalan Puskesmas Pallangga pada umumnya memiliki alur yang panjang. Pasien yang datang berobat mengambil nomor antrian pasien kemudian menuju ke kamar buku untuk memperlihatkan kartu berobat. Pada tahap ini pasien yang seharusnya hanya menunggu antrian panggilan untuk diperiksa tetapi masih harus berjalan menuju kamar buku. Pasien akan kesulitan mengikuti alur pelayanan yang panjang sebelum memasuki ruangan dokter, begitu pula saat pengambilan obat, pasien masih harus menunggu obat disiapkan oleh apoteker. Sistem ini akan menggunakan teknologi websocket. Websocket standar teknologi web untuk melakukan komunikasi secara realtime pada web ataupun aplikasi mobile. Dengan mengimplementasikan Web Socket pada sistem informasi rawat jalan akan mengakibatkan alur proses data bisa menjadi lebih cepat dari sisi transfer dan User Experience dibanding dengan teknologi web native tanpa web socket dapat memudahkan pelayanan pasien rawat jalan di Puskesmas Pallangga.
\end{abstract}

Kata Kunci: Websocket, web base, Sistem, Pelayanan, Pasien, Rawat Jalan, Puskesmas.

\section{PENDAHULUAN}

Puskesmas merupakan salah satu instansi pemerintahan di bidang kesehatan. Puskesmas Pallangga mempunyai peranan sangat penting di Kecamatan Palangga dalam meningkatkan kesehatan masyarakat. Dalam melakukan pelayanan rawat jalan kepada pasien Puskesmas Pallangga memiliki 3 poli, yaitu poli umum, poli gigi, dan poli kesehatan ibu dan anak (KIA). Pada poli umum pemeriksaan pasien terbagi menjadi 3, yaitu pemeriksaan anak, dewasa dan lansia.

Berdasarkan alur proses bisnis pada Puskesmas Kabupaten Gowa, pelayanan pasien rawat jalan memiliki alur yang panjang. Setelah mengambil nomor antrian pasien kemudian menuju ke kamar buku untuk memperlihatkan kartu berobat. Pada tahap ini pasien yang seharusnya hanya menunggu antrian panggilan untuk diperiksa tetapi masih harus berjalan menuju kamar buku. Pasien akan kesulitan mengikuti alur pelayanan yang panjang sebelum memasuki ruangan dokter, begitu pula saat pengambilan obat, pasien masih harus menunggu obat disiapkan oleh apoteker. 
Pada Sistem Pelayanan Pasien Rawat Jalan di Puskesmas Pallangga, websocket akan digunakan pada tahap pendaftaran antrian pasien. Pada saat data antrian pasien telah disimpan maka secara otomatis daftar antrian pemeriksaan awal yang berada di meja perawat akan terisi tanpa melakukan proses reload page pada sistem. Begitu pula saat pemeriksaan awal selesai, maka daftar antrian pemeriksaan lanjutan di meja dokter akan terisi secara otomatis. Daftar antrian obat pada apotik akan terisi secara otomatis saat dokter selesai memeriksa dan menuliskan resep obat pasien.

Websocket merupakan standar baru untuk melakukan komunikasi secara realtime pada web ataupun aplikasi mobile. Pada dasarnya dengan websocket, client dapat menerima data dari server tanpa melakukan request data terlebih dahulu. Berbeda dengan Ajax yang hanya dapat menerima data saat client melakukan request terlebih dahulu kepada server.

Dengan tersedianya sistem informasi rawat jalan berbasis online dengan menggunakan websocket dapat mempercepat proses pelayanan pasien rawat jalan di Puskesmas Pallangga.

Dalam sebuah penelitian oleh Saputro (2017) dengan judul penelitian "Sistem Rekam Medis Rawat Jalan pada Puskesmas Pembantu Sukorejo di Kabupaten Nganjuk". Tujuannya adalah untuk membantu proses rekam medis dengan sistem informasi pendaftaran pasien rawat jalan berupa sebuah aplikasi yang dapat mempermudah dalam pengolahan data pasien. Pembeda dari sistem diatas adalah sistem tersebut menggunakan aplikasi berbasis desktop, sedangkan sistem yang digunakan oleh peneliti saat ini adalah sistem berbasis web secara real time dengan menggunakan websocket.

Kemudian penelitian dari Deviana (2018) dengan judul penelitian "Sistem Informasi Rawat Jalan Pada Puskesmas". Tujuannya adalah memudahkan petugas dalam memperbarui data-data yang masuk serta memudahkan dalam melakukan pencarian data. Pembeda dari kedua penelitian ini adalah bahasa pemrograman yang digunakan. Peneliti diatas menggunakan bahasa pemrograman PHP murni dalam membangun sistemnya, sedangkan peneliti saat ini menggunakan bahasa pemrograman PHP dan Framework CodeIgniter.

Sedangkan penelitian dari Basiroh dan Auliya Burhanuddin (2016) dengan judul penelitian "Sistem Informasi Pengelolaan Data Pasien Rawat Jalan Pada Klinik Akupuntur dan Home Care Sehat Migoenani”. Tujuannya adalah untuk mempermudah sistem yang lama, yang masih manual menjadi sistem informasi yang berbasis komputerisasi, mempercepat pengolahan data dan transaksi, serta mempermudah petugas dalam melaksanakan tugasnya. Pembeda dari kedua penelitian ini adalah peneliti diatas menggunakan Microsoft Visual Foxpro 9.0 dalam mengembangkan sistem ini yang berarti sistem tersebut berbasis dekstop, sedangkan peneliti saat ini menggunakan bahasa pemrograman PHP dan 
Volume 6 Nomor. 1, April 2021

P -ISSN : 2541-1179, E-ISSN : 2581-1711

Ojs :http://journal.uin-alauddin.ac.id/index.php/instek/index

Email : instek@uin-alauddin.ac.id

WFORMATIKASANS DAN TENNOLOCG

Framework CodeIgniter dikarenakan peneliti akan mengembangkan sistem berbasis web.

\section{METODOLOGI PENELITIAN}

Websocket digunakan untuk sistem yang membutuhkan data secepat mungkin dan digunakan agar sistem dapat berjalan secara real time.

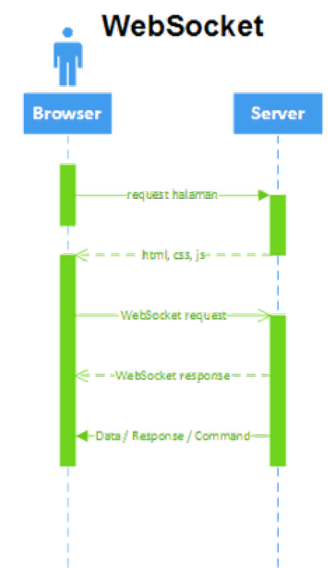

Gambar 1 Alur proses Websocket

Pada gambar 1 terlihat Websocket client hanya melakukan request pada koneksi pertama, kedua dan untuk selanjutnya server dapat merespon tanpa client harus melakukan request terlebih dahulu. Sehingga Websocket mampu menghemat bandwith dan latency jaringan.

\section{a. Pendekatan Penelitian}

Penelitian ini menggunakan pendekatan penelitian saintifik yaitu pendekatan berdasarkan ilmu pengetahuan dan teknologi.

\section{b. Sumber Data}

Sumber data dari penelitian ini berdasarkan dari Library Research yang merupakan cara mengumpulkan data dari beberapa buku, jurnal, skripsi, tesis maupun literatur lainnya yang dapat dijadikan acuan pembahasan dalam masalah ini. Peneliti hanya mengambil beberapa data terkait pada sumber data online atau internet ataupun hasil dari penelitian sebelumnya sebagai bahan referensi bagi peneliti selanjutnya.

\section{c. Metode Pengumpulan Data}

\section{1) Observasi}

Studi lapangan (observasi) merupakan teknik pengumpulan data dengan langsung terjun ke lapangan untuk mengamati permasalahan yang terjadi secara langsung di tempat kejadian secara sistematik kejadian-kejadian, perilaku, objekobjek yang dilihat dan hal-hal lain yang diperlukan dalam mendukung penelitian yang sedang berlangsung. Dalam penelitian ini, peneliti melakukan pengamatan 
secara langsung di Puskesmas Pallangga tentang proses pelayanan pasien rawat jalan di puskesmas tersebut.

2) Wawancara

Wawancara adalah proses tanya jawab yang terjadi antara orang yang mencari informasi (pewawancara) dengan orang yang memberi informasi (narasumber) dengan tujuan untuk mengumpulkan data atau informasi. Dalam penelitian ini peneliti mewawancarai pihak dari Puskesmas Pallangga.

3) Studi Literatur

Studi literatur adalah usaha untuk mempelajari produk-produk temuan ilmiah yang didokumentasikan dalam bentuk tulisan, untuk mendukung dan memperkuat argument dari penelitian baru atau penelitian lanjutan yang sedang dilakukan.

\section{HASIL DAN PEMBAHASAN}

Pada Sistem Pelayanan Pasien Rawat Jalan di Puskesmas Pallangga, websocket akan digunakan pada tahap pendaftaran antrian pasien, pemeriksaan pasien oleh perawat dan dokter, serta saat proses pengambilan obat, agar proses pelayanan dapat dilakukan dengan cepat dan lancar. Komponen websocket yang digunakan pada sistem ini adalah library javascript Socket.IO. Dengan library javascript Socket.IO, client dan server dapat melakukan pengiriman dan penerimaan data secara realtime. Socket.IO terdiri dari dua bagian, yang pertama adalah client-side yang berjalan pada browser dan yang kedua adalah server-side yang digunakan sebagai modul untuk node.js.

1. Implementasi Aplikasi

Tahap implementasi sistem merupakan tahap menerjemahkan perancangan berdasarkan hasil analisis dalam bahasa yang dapat dimengerti oleh mesin serta penerapan perangkat lunak pada keadaan yang sesungguhnya.

a. Implementasi Script di sisi server

Dalam menjalankan server Socket.IO ini hal yang pertama harus dilakukan adalah mengaktifkannya melalui CLI (Command Line Interface) agar dapat mengirim pesan dan menerima pesan dengan perintah node server.js pada terminal.

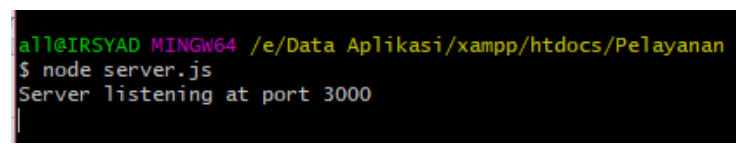

Gambar 2 Script menjalankan server node.js

Adapun isi file dari server.js dapat dilihat pada gambar 3. Pada baris 17, terdapat perintah 'reload_data' yang akan digunakan untuk memuat data saat melakukan pemanggilan ke server. 


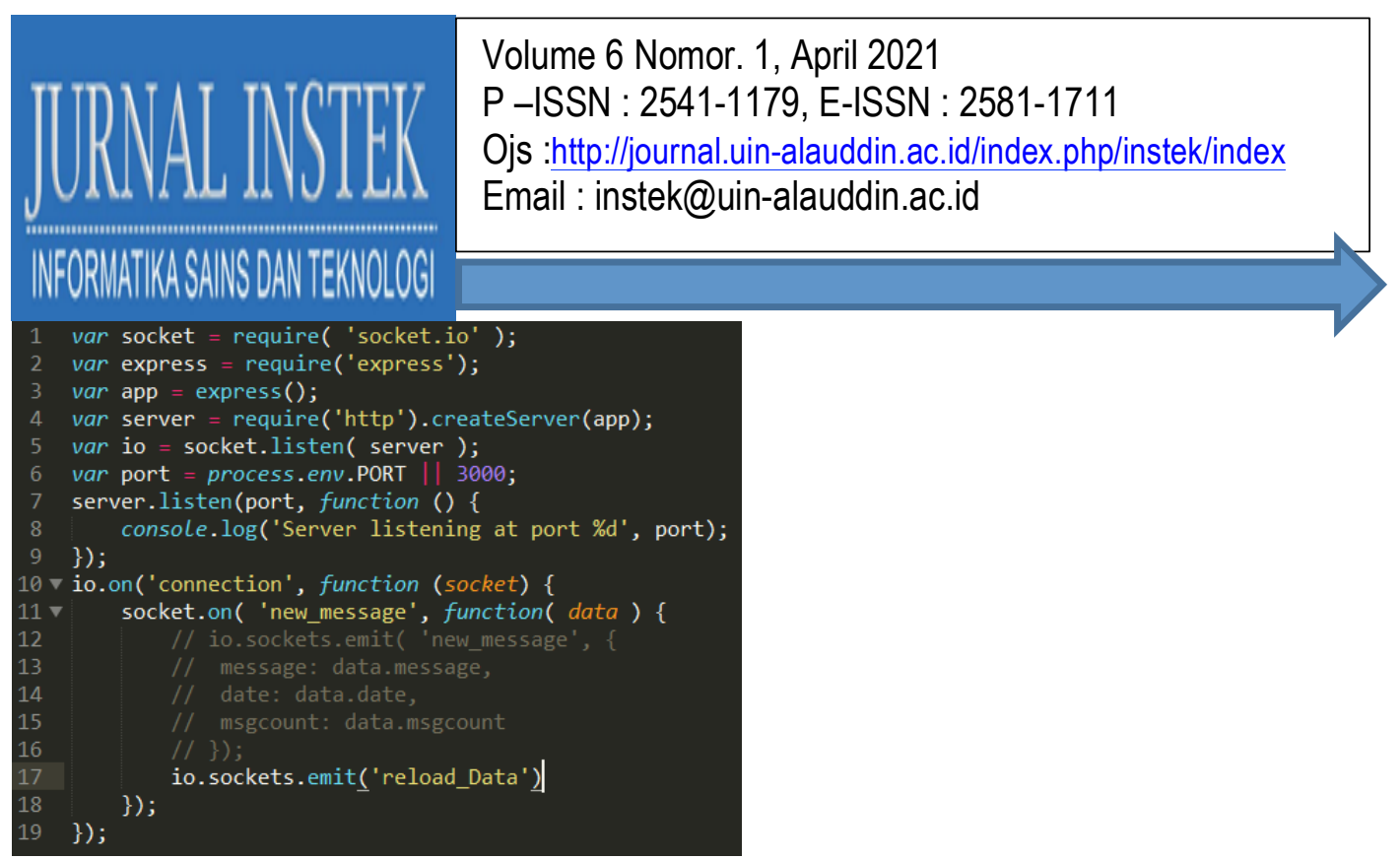

Gambar 3 Script server Socket.IO

b. Implementasi Script di sisi client

Pada gambar 4 baris 143 penggunaan emit() berfungsi untuk mengirimkan sebuah pesan dari server ke client dan dari client ke server.

\begin{tabular}{l|c|}
140 & \$('\#simpan').click(function(argument) \{ \\
141 & $/ / \$(' \#$ demo-form2').submit(); \\
142 & console.log() \\
143 & socket.emit('new_message') \\
144 & \})
\end{tabular}

Gambar 4 Script untuk mengirim data

Pada gambar 5 baris 69 penggunaan method on() berfungsi untuk menerima data yang kemudian akan diproses oleh fungsi handler. Fungsi handler pada gambar 5 baris 72 yaitu untuk memuat ulang halaman client.

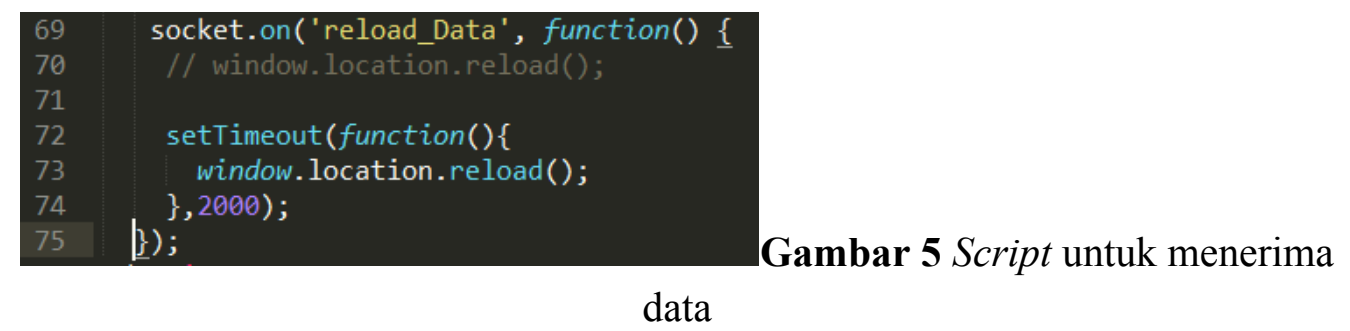

2. Pengujian Aplikasi

a. Pengujian Fungsional Aplikasi

Pada sistem dilakukan pengujian berdasarkan fungsinya. Sistem diakses oleh staf yang akan memasukkan data antrian pasien dan secara langsung akan masuk ke daftar antrian. 


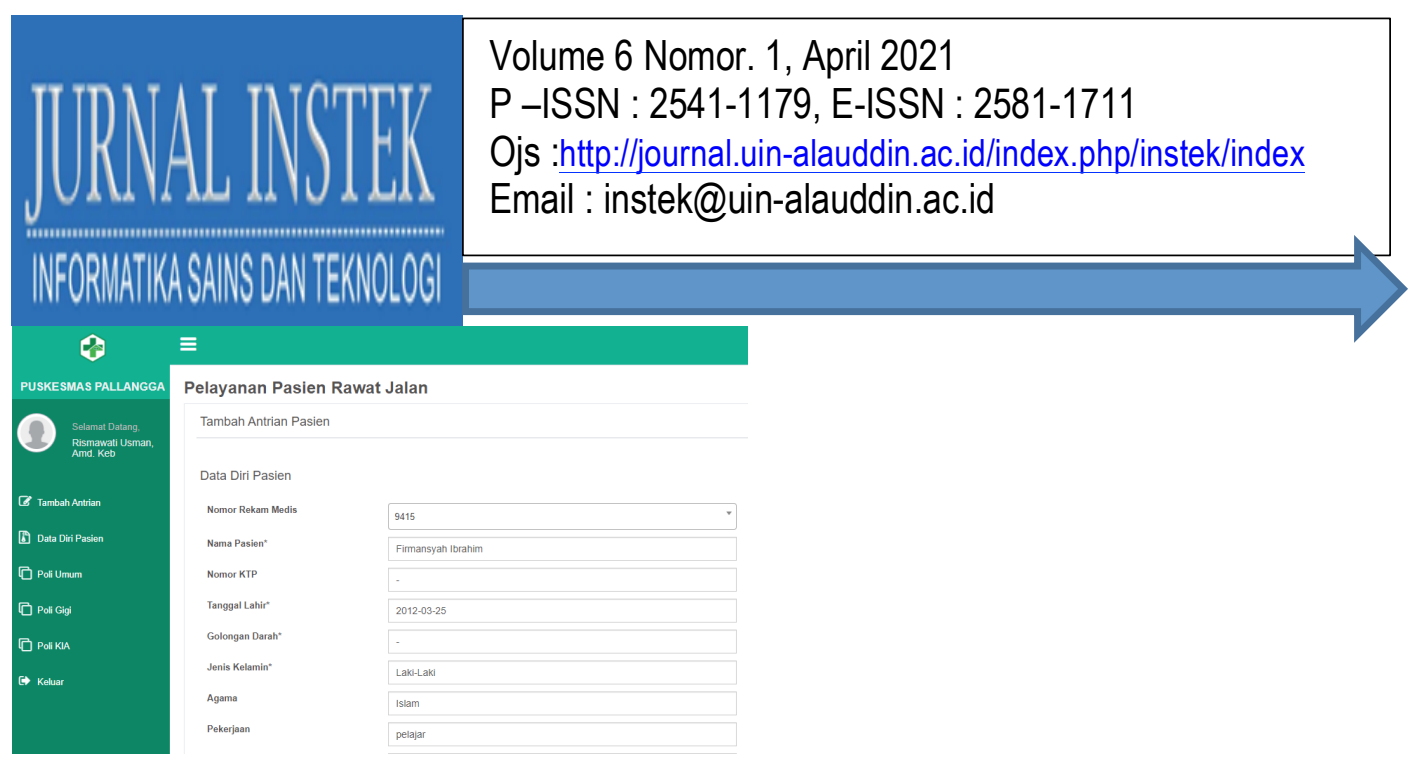

Gambar 6 Tampilan Input daftar antrian

Pada gambar 7 daftar antrian yang telah dimasukkan oleh staf akan tampil secara real time.

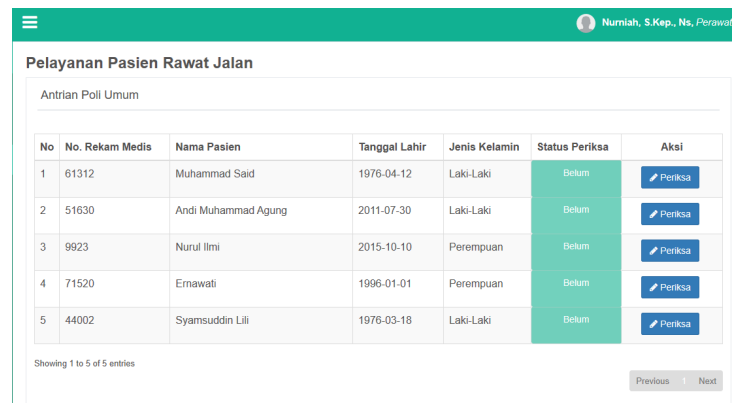

Gambar 7 Tampilan daftar antrian

b. Pengujian Performa Aplikasi

Pada sistem dilakukan pengujian performa dengan melihat kecepatan saat halaman mengirim dan menerima data. Tools yang digunakan adalah bawaan dari browser google chrome yaitu Chrome DevTools. Chrome DevTools ini dapat digunakan untuk mengecek kecepatan website dan mendapatkan laporannya dengan menekan Ctrl+Shift + I pada keyboard.

Pada gambar 8, terlihat hasil tes saat halaman staf mengirim data pada Chrome DevTools. Sedangkan pada gambar 9 adalah hasil tes saat halaman perawat menerima data dari halaman staf.

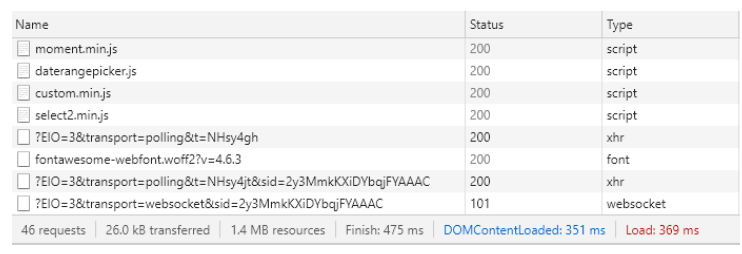

Gambar 8 Hasil tes halaman staf mengirim data 
Volume 6 Nomor. 1, April 2021

P -ISSN : 2541-1179, E-ISSN : 2581-1711

Ojs :http://journal.uin-alauddin.ac.id/index.php/instek/index

Email : instek@uin-alauddin.ac.id

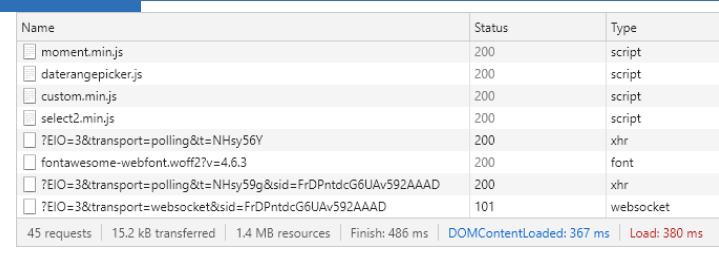

Gambar 9 Hasil tes halaman perawat menerima data

Lebih jelasnya terdapat pada tabel 1 yang menunjukkan hasil pengujian kecepatan halaman staf mengirim data ke halaman perawat. Sedangkan pada tabel 2 adalah hasil pengujian kecepatan halaman perawat saat menerima data dari halaman staf.

Tabel 1 Halaman Staf mengirim data

\begin{tabular}{cccc}
\hline Objek & $\begin{array}{c}\text { Page } \\
\text { size }\end{array}$ & $\begin{array}{c}\text { Load } \\
\text { Time }\end{array}$ & $\begin{array}{c}\text { Reques } \\
\boldsymbol{t}\end{array}$ \\
\hline $\begin{array}{c}\text { Halaman } \\
\text { Staf }\end{array}$ & $1.4 \mathrm{MB}$ & $369 \mathrm{~ms}$ & 46 \\
\hline
\end{tabular}

Tabel 2 Halaman Perawat menerima data

\begin{tabular}{cccc}
\hline Objek & $\begin{array}{c}\text { Page } \\
\text { size }\end{array}$ & $\begin{array}{c}\text { Load } \\
\text { Time }\end{array}$ & $\begin{array}{c}\text { Reques } \\
\boldsymbol{t}\end{array}$ \\
\hline $\begin{array}{c}\text { Halaman } \\
\text { Perawat }\end{array}$ & $1.4 \mathrm{MB}$ & $380 \mathrm{~ms}$ & 45 \\
\hline
\end{tabular}

Pada gambar 10, terlihat hasil tes saat halaman perawat mengirim data pada Chrome DevTools. Sedangkan pada gambar 11 adalah hasil tes saat halaman dokter menerima data dari halaman perawat.

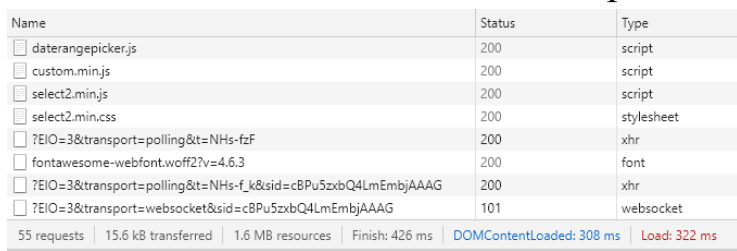

Gambar 10 Hasil tes halaman perawat mengirim data

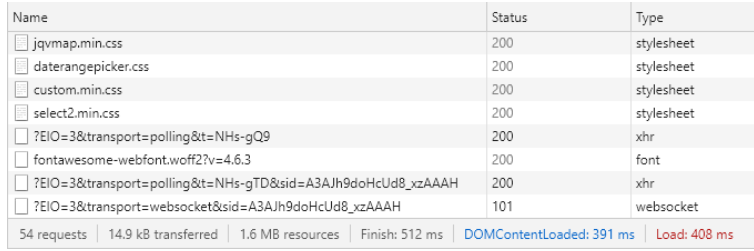

Gambar 11 Hasil tes halaman dokter menerima data 
Volume 6 Nomor. 1, April 2021

P -ISSN : 2541-1179, E-ISSN : 2581-1711

Ojs :http://journal.uin-alauddin.ac.id/index.php/instek/index

Email : instek@uin-alauddin.ac.id

\section{WNEORMATIKA SANSSDAN TEKNOLOG}

Lebih jelasnya terdapat pada tabel 3 yang menunjukkan hasil pengujian kecepatan halaman perawat mengirim data ke halaman dokter. Sedangkan pada tabel 4 adalah hasil pengujian kecepatan halaman dokter saat menerima data dari halaman perawat.

Tabel 3 Halaman Perawat mengirim data

\begin{tabular}{cccc}
\hline Objek & $\begin{array}{c}\text { Page } \\
\text { size }\end{array}$ & $\begin{array}{c}\text { Load } \\
\text { Time }\end{array}$ & $\begin{array}{c}\text { Reques } \\
\boldsymbol{t}\end{array}$ \\
\hline $\begin{array}{c}\text { Halaman } \\
\text { Perawat }\end{array}$ & $1.6 \mathrm{MB}$ & $322 \mathrm{~ms}$ & 55 \\
\hline
\end{tabular}

Tabel 4 Halaman Dokter menerima data

\begin{tabular}{cccc}
\hline Objek & $\begin{array}{c}\text { Page } \\
\text { size }\end{array}$ & $\begin{array}{c}\text { Load } \\
\text { Time }\end{array}$ & $\begin{array}{c}\text { Reques } \\
\boldsymbol{t}\end{array}$ \\
\hline $\begin{array}{c}\text { Halaman } \\
\text { Dokter }\end{array}$ & $1.6 \mathrm{MB}$ & $408 \mathrm{~ms}$ & 54 \\
\hline
\end{tabular}

Pada gambar 12, terlihat hasil tes saat halaman dokter mengirim data pada Chrome DevTools. Sedangkan pada gambar 13 adalah hasil tes saat halaman apoteker menerima data dari halaman dokter

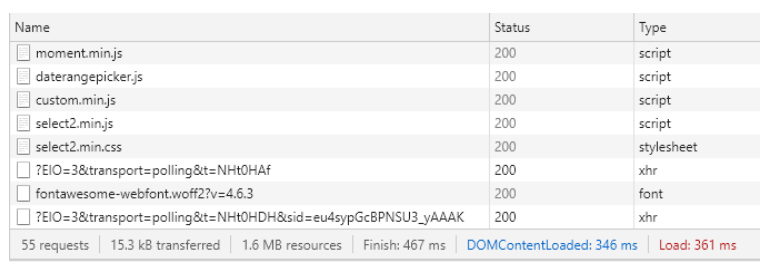

Gambar 12 Hasil tes halaman dokter mengirim data

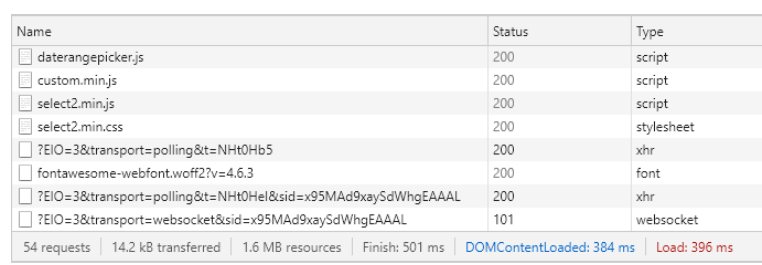

Gambar 13 Hasil tes halaman apoteker menerima data

Lebih jelasnya terdapat pada tabel 5 yang menunjukkan hasil pengujian kecepatan halaman dokter mengirim data ke halaman apoteker. Sedangkan pada tabel 6 adalah hasil pengujian kecepatan halaman apoteker saat menerima data dari halaman dokter. 


\section{NEORMATIKASANS DANTEKNOLOOG}

Tabel 5 Halaman Dokter mengirim data

\begin{tabular}{cccc} 
Objek & $\begin{array}{c}\text { Page } \\
\text { size }\end{array}$ & $\begin{array}{c}\text { Load } \\
\text { Time }\end{array}$ & $\begin{array}{c}\text { Reques } \\
\boldsymbol{t}\end{array}$ \\
\hline $\begin{array}{c}\text { Halaman } \\
\text { Dokter }\end{array}$ & $1.6 \mathrm{MB}$ & $361 \mathrm{~ms}$ & 55 \\
\hline
\end{tabular}

Tabel 6 Halaman Apoteker menerima data

\begin{tabular}{cccc}
\hline Objek & $\begin{array}{c}\text { Page } \\
\text { size }\end{array}$ & $\begin{array}{c}\text { Load } \\
\text { Time }\end{array}$ & $\begin{array}{c}\text { Reques } \\
\boldsymbol{t}\end{array}$ \\
\hline $\begin{array}{c}\text { Halaman } \\
\text { Apoteker }\end{array}$ & $1.6 \mathrm{MB}$ & $396 \mathrm{~ms}$ & 54 \\
\hline
\end{tabular}

Berdasarkan pengujian performa dengan melihat kecepatan sistem saat mengirim dan menerima data menggunakan Chrome DevTools. Load time dari keseluruhan sistem yang diuji membutuhkan waktu memuat halaman dibawah 1 detik. Dengan hasil tersebut sistem dapat digunakan dengan cepat.

\section{KESIMPULAN}

Adapun kesimpulan dari penelitian ini yang dapat diambil adalah dengan adanya sistem berbasis website serta teknologi websocket, penggunaan sistem secara real time dapat mempermudah Staf Puskesmas Pallangga dalam pelayanan Pasien. Dikarenakan data yang telah diinput oleh staf akan secara langsung tampil pada daftar antrian tanpa melakukan request data terlebih dahulu. Pasien yang datang berobat lebih cepat dilayani dikarenakan staf tidak perlu lagi mencari buku rekam medis pasien pada kamar buku.

\section{DAFTAR PUSTAKA}

Basiroh dan Auliya Burhanuddin. (2016). Sistem Informasi Pengelolaan Data Pasien Rawat Jalan Pada Klinik Akupuntur dan Home Care Sehat Migoenani.

Deviana, Prista Avinda. (2018). Sistem Informasi Rawat Jalan Pada Puskesmas.

Saputro, Yayan Bagus. (2017). Sistem Rekam Medis Rawat Jalan Pada Puskesmas Pembantu Sukorejo Di Kabupaten Nganjuk. 